\title{
Indicadores de qualidade de Latossolo Vermelho sob diferentes usos ${ }^{1}$
}

\author{
Aurélio Alves Amaral Chaves ${ }^{2}$, Marilusa Pinto Coelho Lacerda ${ }^{2}$, \\ Wenceslau J. Goedert ${ }^{2}$, Maria Lucrécia Gerosa Ramos², Eiyti Kato ${ }^{2}$
}

\begin{abstract}
Quality indicators of Red Latosol under different uses

The evaluation and monitoring of soil quality, in the micro-drainage basins which contribute directly to the Rio Descoberto reservoir, in the Rio Descoberto drainage basin, Distrito Federal (DF), Brazil, are necessary, due to its disordered rural occupation. Thus, this study aimed at evaluating the quality indicators of Red Latosol (RL), in micro-drainage basins located in the northern Rio Descoberto drainage basin, under diversified uses and managements: Savannah (SA), reforestation (RF), native pasture (NP), cultivated pasture (CP), agriculture with covered soil (AC) and agriculture with partial soil covering (AP). Soil density (SD) presented the lowest value for SA and the highest one for AP. The CP area showed the highest values for soil resistance to penetration, reflecting the effect of animal trampling. The highest value for organic matter (OM) was $55.5 \mathrm{~g} \mathrm{~kg}^{-1}$, in the CP, and the lowest one was observed in the $\mathrm{AC}\left(37.5 \mathrm{~g} \mathrm{~kg}^{-1}\right)$, where decomposition processes are favored. The cation exchange capacity varied from $7.80 \mathrm{cmol}_{\mathrm{c}} \mathrm{dm}^{-3}$ (NP) to $9.75 \mathrm{cmol}_{\mathrm{c}} \mathrm{dm}^{-3}$ (RF), pointing out the liming effect. The values obtained for microbial biomass carbon and basal respiration showed positive effects of the grass root system in the development of microorganisms. Among the soil quality attributes evaluated, the $\mathrm{OM}$ and SD stood out, confirming that a more intensive agricultural activity is directly related to the quality reduction of the RL evaluated.
\end{abstract}

KEY-WORDS: Soil attributes; soil management; micro-drainage basins.

\section{INTRODUÇÃO}

Os solos constituem-se em um dos mais importantes componentes dos ecossistemas terrestres, sob os aspectos produtivo e social, além de apresentarem diversas funções ecológicas. No entanto, os mesmos vêm apresentando ocupação rural desordenada, em função do grande crescimento populacional do território brasileiro, fato que compromete a sua qualidade.

\section{RESUMO}

A avaliação e o monitoramento da qualidade dos solos das microbacias que contribuem diretamente para o Reservatório do Rio Descoberto, na Bacia do Rio Descoberto, no Distrito Federal (DF), tornam-se necessários, em função da ocupação rural desordenada. Assim, este trabalho objetivou avaliar indicadores de qualidade de Latossolo Vermelho (LV), em microbacias da parte norte da Bacia do Rio Descoberto, com usos e manejos diversificados: Cerrado (CE), reflorestamento (RF), pastagem nativa $(\mathrm{PN})$, pastagem plantada $(\mathrm{PP})$, agricultura com solo coberto (AC) e agricultura com cobertura parcial do solo (AP). A densidade do solo (DS) apresentou o menor valor para CE e o maior para AP. A área de PP foi a que apresentou os maiores valores de resistência do solo à penetração, refletindo o efeito do pisoteio de animais. O maior valor para a matéria orgânica (MO) foi de $55,5 \mathrm{~g} \mathrm{~kg}^{-1}$, na PP, e o menor valor foi observado na $\mathrm{AC}\left(37,5 \mathrm{~g} \mathrm{~kg}^{-1}\right)$, ambiente onde processos de decomposição são favorecidos. A capacidade de troca catiônica variou de $7,80 \mathrm{cmol}_{c} \mathrm{dm}^{-3}(\mathrm{PN})$ a $9,75 \mathrm{cmol}_{c} \mathrm{dm}^{-3}(\mathrm{RF})$, mostrando o efeito da calagem. Os valores obtidos para o carbono da biomassa microbiana e respiração basal indicaram efeitos positivos do sistema radicular das gramíneas, no desenvolvimento de microorganismos. Dentre os atributos de qualidade do solo avaliados, destacaram-se a MO e a DS, que permitiram constatar que o uso agropecuário mais intensivo está diretamente relacionado à redução na qualidade do LV estudado.

PALAVRAS-CHAVE: Atributos do solo; manejo do solo; microbacias.

Para Doran \& Parkin (1994), a qualidade do solo pode ser definida como a sua capacidade de desempenhar funções em um ecossistema, como suportar plantas e animais, resistir à erosão e reduzir impactos negativos associados aos recursos água e ar. A preocupação com a qualidade do solo tem crescido, à medida em que o seu uso e mobilização intensiva possam redundar na diminuição da sua capacidade de manter uma produção biológica sustentável (Carvalho et al. 2004).

1. Trabalho recebido em nov./2011 e aceito para publicação em nov./2012 ( ${ }^{\circ}$ registro: PAT 16229).

2. Universidade de Brasília (UnB), Faculdade de Agronomia e Medicina Veterinária, Brasília, DF, Brasil.

E-mails: aaa.chaves@hotmail.com,marilusa@unb.br, goedert@unb.br, lucrecia@unb.br, kato@unb.br. 
O nível de alteração na qualidade do solo (QS) pode ser avaliado pela mensuração do estado atual de determinados atributos e a comparação destes com os seus correspondentes no estado natural do solo, sem interferência antrópica, ou com valores que são considerados ideais (Doran \& Parkin 1994). Neste caso, as dificuldades residem em selecionar quais propriedades serão avaliadas e definir os valores considerados adequados ou ideais, os quais podem variar, de acordo com a classe de solo investigada (Arshad \& Martin 2002).

Uma das propostas mais objetivas sugere definir, explicitamente, as funções que determinam a QS, identificar os atributos de cada função e, então, selecionar um conjunto mínimo de indicadores, para medir cada uma destas funções previamente definidas (Doran \& Parkin 1994, Nortcliff 2002). No entanto, Goedert et al. (2002) entendem que existe falta de consenso entre pesquisadores, sobre o nível crítico definido para os atributos físicos dos solos, em relação à QS. Levando-se isto em conta, Goedert (2005) propôs limites de qualidade do solo, em sistemas de produção agrícola, nos quais, para diversos indicadores de QS, são apresentados níveis de sustentabilidade, para a camada superficial de latossolos das regiões tropicais.

Assim, a literatura mostra vários trabalhos envolvendo a análise de atributos físicos, químicos e biológicos dos solos, que podem ser utilizados para avaliar diferentes usos e manejos, em estudos de sustentabilidade dos solos, podendo-se citar, dentre outros, os de Alvarenga \& Davide (1999), D'Andrea et al. (2002) e Melloni et al. (2008). No Distrito Federal, destaca-se o trabalho realizado por Araújo et al. (2007), no qual o estudo de atributos químicos, físicos e biológicos de um Latossolo Vermelho, sob tipos diferenciados de uso e ocupação, permitiu avaliar a sustentabilidade do Latossolo estudado, a qual mostrou-se distinta, nos usos diversificados.

Os atributos físicos são usados para estimar a condição de estruturação dos solos, com relação ao potencial de lixiviação, produtividade e aspectos erosivos, sendo afetados por vários fatores, como o sistema de manejo, tipo de cobertura vegetal, quantidade de resíduos à superfície e teor de matéria orgânica (Doran \& Parkin 1994, Tormena et al. 2002, Cruz et al. 2003, Spera et al. 2006).

Outro fato importante a ser considerado é que as terras do Distrito Federal (DF) vêm sofrendo grande pressão, pela ocupação rural desordenada, em função do grande crescimento populacional. Inserida neste cenário, está a Bacia do Rio Descoberto, uma área muito importante para a região, formada por importantes microbacias, cujas drenagens abastecem o Reservatório do Rio Descoberto, responsável pelo fornecimento de água a cerca de $60 \%$ da população do DF e entorno. Esta área vem sendo ambientalmente comprometida, pelo aumento da utilização agrícola sem manejo adequado, tanto nas margens do Reservatório quanto nos seus tributários diretos.

Diante do exposto, constata-se a necessidade de avaliação e monitoramento da qualidade dos solos das microbacias que contribuem diretamente para o Reservatório do Rio Descoberto. Assim, o presente trabalho objetivou avaliar atributos relacionados à qualidade do Latossolo Vermelho, sob diferentes usos e manejos, nas microbacias dos córregos Barrocão, Bucanhão e Capão da Onça, tributários da porção norte do Rio Descoberto, a fim de subsidiar estudos de sustentabilidade do uso destas áreas.

\section{MATERIAL E MÉTODOS}

A área de estudo localiza-se na porção norte da Bacia do Rio Descoberto, englobando as microbacias dos córregos Barrocão, Bucanhão e Capão da Onça, na Região Administrativa de Brazlândia (DF), e possui 6.583 ha, sendo delimitada pelas coordenadas UTM (fuso 23S) $795.624 \mathrm{~m}$ a $807.260 \mathrm{~m}$ e 8.261.264 $\mathrm{m}$ a $8.272 .752 \mathrm{~m}$.

O relevo da área é predominantemente plano a suave ondulado, e a vegetação natural é o Cerrado. Segundo Fonseca (2001), o clima predominante, pela classificação de Köppen, é o "tropical de Savana", com concentração da precipitação pluviométrica no verão.

O Latossolo Vermelho (LV) foi caracterizado e classificado em um local com desenvolvimento de vegetação de Cerrado típico. A descrição morfológica e a coleta de amostras foram feitas segundo normas descritas por Santos et al. (2005).

Foram realizadas análises físicas e químicas, nos horizontes A e Bw do perfil descrito, com três repetições (Embrapa 1997). O Latossolo estudado apresenta baixa capacidade de troca cationica (CTC a pH 7,0), com valores de $6,83 \mathrm{cmol}_{\mathrm{c}} \mathrm{dm}^{-3}$ e $6,78 \mathrm{cmol}_{\mathrm{c}} \mathrm{dm}^{-3}$, nos horizontes A e Bw, respectivamente, e baixa saturação por bases ( $\mathrm{V}$ da CTC a $\mathrm{pH} 7,0$ de $3,86 \%$ e $3,13 \%$, respectivamente, nos 
horizontes A e $\mathrm{Bw})$, conferindo o caráter distrófico. Apresenta, ainda, teor de matéria orgânica (MO) considerado intermediário $\left(38,3 \mathrm{~g} \mathrm{~kg}^{-1} \mathrm{e} 22,0 \mathrm{~g} \mathrm{~kg}^{-1}\right.$, nos horizontes $\mathrm{A}$ e $\mathrm{Bw}$, respectivamente), em relação aos teores médios dos solos sob Cerrado.

O solo apresenta relação silte/argila muito baixa $(0,11)$, na maior parte do horizonte $\mathrm{Bw}$, indicando estágio avançado de intemperização. Observou-se, ainda, que o LV avaliado não possui características que indiquem a presença de compactação, uma vez que apresenta baixa densidade do solo $\left(0,88 \mathrm{~g} \mathrm{~cm}^{-3} \mathrm{e}\right.$ $0,92 \mathrm{~g} \mathrm{~cm}^{-3}$, nos horizontes A e Bw, respectivamente) e alta porosidade total (Volume Total de Poros de $65,64 \%$ e $63,46 \%$, nos horizontes A e Bw, respectivamente).

Com base na descrição morfológica e nos resultados das análises, o solo foi classificado como Latossolo Vermelho distrófico típico, A moderado, de textura muito argilosa (Embrapa 2006). A avaliação dos atributos relacionados à qualidade do solo foi feita em seis áreas amostrais, descritas a seguir:

- Cerrado (CE): Área de Cerrado Típico, caracterizado por uma camada arbórea descontínua, atingindo $8,0 \mathrm{~m}$ de altura, excepcionalmente mais alta, cobrindo de $10 \%$ a $60 \%$ da superfície, e um estrato herbáceo-arbustivo bastante diversificado, com cobertura de até 95\%. Área destituída de qualquer uso antrópico;

- Reflorestamento (RF): Área com indivíduos adultos de Pinus sp., plantados há mais de 20 anos, com correção e adubação do solo somente no plantio. Possui serapilheira recobrindo todo o solo do local, chegando a 10,0 cm de cobertura de acículas. Não foi observada a presença de nenhum tipo de vegetação, seja de sub-bosque, arbustiva ou rasteira;

- Pastagem Nativa (PN): Área com vegetação de Cerrado Ralo ou Campo Cerrado, ou seja, forma intermediária de vegetação entre o Cerrado Típico e o Campo Sujo. Seu dossel atinge, em média, 10\% de cobertura, com árvores alcançando mais de 3,0 m de altura, bem espalhadas. Pelas características e relatos dos responsáveis pela exploração da propriedade, esta área foi utilizada como pastagem para bovinos e equinos, sem controle de lotação e tratos culturais. No período em que foi realizado o estudo, a área encontrava-se em pousio há cerca de um ano;

- Pastagem Plantada (PP): Área cultivada com Brachiaria decumbens, em um piquete de, aproximadamente, 10,0 ha. Aárea foi arada, nivelada, corrigida e quimicamente adubada, há, aproximadamente, cin- co anos. Na ocasião do desenvolvimento do trabalho e coleta de amostras, a lotação máxima desta área correspondia a 25 cabeças de gado leiteiro;

- Agricultura com Cobertura Parcial do Solo (AP): Área cultivada com hortaliças (Brassica oleracea Capitata), com grande percentual de solo exposto. Após cada cultivo, é efetuada a aração com enxada rotativa, adubação química e correção do solo. A irrigação por aspersão é utilizada quando o agricultor considera o solo seco;

- Agricultura com Solo Coberto (AC): Área cultivada com mandioca (Manihot esculenta Crantz), em estágio avançado de desenvolvimento, bem adensada e recobrindo, uniformemente, o solo. Após cada cultivo, é efetuada a aração com enxada rotativa, adubação química e correção do solo.

As duas culturas, nas áreas de agricultura, foram selecionadas em função do grau de exposição do solo, para avaliar este efeito na qualidade do mesmo.

As seis áreas amostrais foram selecionadas por serem representativas do uso e ocupação das terras da área estudada, com base em informações apresentadas por Chaves et al. (2010), sobre a quantificação dos usos e ocupações das terras da mesma microbacia. Segundo Chaves et al. (2010), a área de reflorestamento avaliada apresenta 47,67 ha, que, juntamente com matas ciliares e de galeria, constituem $10,68 \%$ da área total da microbacia. As áreas de pastagem avaliadas (PN e PP) possuem 1,16 ha e 9,27 ha, respectivamente, e contribuem para 54,94\% da área total de pastagem desta microbacia. Por sua vez, a agricultura corresponde a $21,59 \%$ da área total da microbacia e foi avaliada nas áreas amostrais de AP (1,53 ha) e AC ( 0,9 ha). Por fim, o Cerrado ocupa $12,79 \%$ da área total da microbacia e foi estudado em uma área de 35,50 ha.

A coleta das amostras, para caracterização dos atributos relacionados à qualidade do solo, foi realizada à profundidade de $0,0-10,0 \mathrm{~cm}$, indicada, em vários estudos (Kondo \& Dias Júnior 1999, Araújo et al. 2007), como sendo a que apresenta maior resposta das alterações destes atributos, em relação ao tipo de manejo efetuado, pelo acúmulo de resíduos orgânicos, manejo de implementos agrícolas e pressões físicas exercidas sobre o solo. Já a resistência à penetração vertical (RP) foi medida, também, à profundidade de 10,0-20,0 cm, por considerar-se que, até esta profundidade, verifica-se a maior probabilidade de se evidenciar a ocorrência de compactação (Beutler et al. 2001, Araújo et al. 2007), principalmente em 
manejos que utilizam implementos agrícolas que movimentam as camadas mais superficiais do solo.

Para a coleta das amostras, foi projetada uma linha diagonal imaginária, ao longo de cada área amostral, com três pontos equidistantes, representando as repetições. Nas áreas ocupadas por agricultura (AC, AP e RF), as coletas foram feitas ao longo das linhas de cultivo. A amostragem para análise da RP foi feita em pequenas trincheiras, para a retirada da amostra com 10,0-20,0 cm.

As amostras de solo foram coletadas ao término do período chuvoso, em abril de 2005, e os atributos avaliados para comparação da QS entre as áreas amostrais foram:

- Atributos Físicos: A densidade do solo (DS) foi obtida por meio de amostras indeformadas, coletadas pelo método do anel volumétrico de $10,0 \mathrm{~cm}$ de altura, pela média de três repetições, em cada ponto amostral (Embrapa 1997). Para a determinação da resistência à penetração vertical (RP), foi utilizado penetrômetro Eijkelkamp-Giesbeek, modelo 06.01. SA (Hand penetrometer Eijkelkamp, for measurements to a depth of $1.0 \mathrm{~m}$ ), com comprimento de haste de 40,0 cm, diâmetro da ponteira de $1,5 \mathrm{~cm}$ e ângulo do cone de $60^{\circ}$. A RP foi obtida pela média de 15 leituras, realizadas em cada área amostral, às profundidades de $0,0-10,0 \mathrm{~cm}$ e $10,0-20,0 \mathrm{~cm}$. Para esta análise, foi determinada a umidade do Latossolo Vermelho das áreas amostrais, para o controle da interferência da mesma na RP;

- Atributos Químicos: A matéria orgânica (MO) e a capacidade de troca catiônica (CTC) foram determinadas segundo metodologias descritas pela Embrapa (1997). Foram retiradas cinco amostras deformadas simples, em cada ponto amostral, para constituir amostras compostas, coletadas à profundidade de 0,0-10,0 cm, com três repetições por área amostral;

- Atributos Biológicos: Foram coletadas, no campo, amostras compostas, constituídas por cinco amostras deformadas simples, nos pontos amostrados, de cerca de $500,0 \mathrm{~g}$ cada, coletadas à profundidade de 0,0-10,0 cm, com três repetições por área amostral. As amostras compostas foram devidamente armazenadas em sacos plásticos hermeticamente lacrados, acondicionadas em caixas de isopor refrigeradas e transportadas diretamente para o Laboratório de Biologia do Solo da Faculdade de Agronomia e Medicina Veterinária da Universidade de Brasília, onde foram devidamente mantidas em refrigeradores.
O método utilizado para a determinação do carbono da biomassa microbiana (Cmic) foi o da fumigação e incubação (FI) (Jenkinson \& Powlson 1976), e a respiração basal (Rmic) foi medida pela quantidade de $\mathrm{CO}_{2}$ desprendido pelos micro-organismos da amostra de solo incubada (Alef 1995).

Os dados foram analisados estatisticamente, utilizando-se delineamento inteiramente casualizado (Anova), por meio do software SAS. Para a análise da RP, o delineamento experimental foi inteiramente casualizado, com o tratamento na parcela e as profundidades na subparcela. A comparação de médias foi feita pelo teste Tukey, a 5\%.

\section{RESULTADOS E DISCUSSÃO}

\section{Atributos fisicos}

Observou-se relação direta entre a densidade e o tipo de uso do solo (Tabela 1). As áreas amostrais que possuem exploração agrícola apresentaram maiores valores de DS, em comparação com a área de Cerrado (CE), a qual não diferiu dos demais usos. A área de agricultura com cobertura parcial do solo (AP) apresentou maior DS do que aquela sob agricultura com solo coberto (AC). A DS, nas áreas de pastagem (PN e PP), reflorestamento (RF) e AC, não diferiram entre si.

$\mathrm{O}$ maior valor de DS, na área de agricultura com cobertura parcial do solo (AP), pode ser explicado pela ação de máquinas e pelo uso intensivo, que ocasionam maior pressão no solo, semelhantemente ao descrito por Mentges et al. (2010). O valor observado encontra-se dentro das médias de densidade relatadas por Camargo \& Alleoni (1997) e Lal (1999), que consideram que o solo de textura argilosa, com DS inferior a $1,2 \mathrm{~g} \mathrm{~cm}^{-3}$, não apresenta limitação ao sistema radicular, e por Dexter (2004), que cita valores médios de densidade para solos argilosos de 1,0-1,2 $\mathrm{g} \mathrm{cm}^{-3}$. Porém, o valor de DS, na área AP, está acima dos valores considerados limítrofes, ou seja, inferiores a $1,0 \mathrm{~g} \mathrm{~cm}^{-3}$, para qualidade de latossolos tropicais de textura argilosa, tanto em solos sob uso agrícola (Goedert 2005), como sob vegetação nativa (Papa et al. 2011).

Como a DS possui estreita relação com outros atributos físicos do solo, o aumento da mesma está associado à diminuição da porosidade total, macroporosidade, condutividade hidráulica e absorção iônica, assim como ao consequente aumento da 
Tabela 1. Densidade do solo (DS) e resistência à penetração (RP), em áreas sob diferentes usos da terra (Brazlândia, DF, 2005).

\begin{tabular}{|c|c|c|c|}
\hline \multirow{4}{*}{ Usos da terra } & \multicolumn{3}{|c|}{ Profundidade $(\mathrm{cm})$} \\
\hline & $0,0-10,0$ & $0,0-10,0$ & $10,0-20,0$ \\
\hline & DS & \multicolumn{2}{|c|}{ RP } \\
\hline & $\mathrm{g} \mathrm{cm}^{-3}$ & \multicolumn{2}{|c|}{$\mathrm{MPa}-$} \\
\hline Agricultura com cobertura parcial do solo (AP) & $1,09 \mathrm{~A}$ & $0,31 \mathrm{CD}$ a & $0,36 \mathrm{D}$ a \\
\hline Agricultura com solo coberto (AC) & $0,89 \mathrm{~B}$ & $0,27 \mathrm{D}$ a & $0,32 \mathrm{D}$ a \\
\hline Pastagem nativa $(\mathrm{PN})$ & $0,88 \mathrm{BC}$ & $0,45 \mathrm{~B} \mathrm{~b}$ & $0,91 \mathrm{~B} \mathrm{a}$ \\
\hline Pastagem plantada (PP) & $0,84 \mathrm{BC}$ & $0,82 \mathrm{~A} \mathrm{~b}$ & $1,62 \mathrm{~A} \mathrm{a}$ \\
\hline Reflorestamento (RF) & $0,78 \mathrm{BC}$ & $0,42 \mathrm{BC} \mathrm{b}$ & $0,53 \mathrm{C} \mathrm{a}$ \\
\hline Cerrado (CE) & $0,76 \mathrm{C}$ & $0,28 \mathrm{CD} \mathrm{b}$ & $0,56 \mathrm{C} \mathrm{a}$ \\
\hline Valor de F & 22,96 & 64,72 (uso) & 213,99 (profundidade) \\
\hline C.V. $(\%)$ & 4,87 & 41,32 (uso) & 23,53 (profundidade) \\
\hline
\end{tabular}

microporosidade e da resistência mecânica à penetração (Mercante et al. 2003, Melo Filho et al. 2006, Mendes et al. 2006). Estas alterações na qualidade física do solo desencadeiam, no geral, a diminuição da produtividade agrícola (Foloni et al. 2003, Secco et al. 2005, Santos et al. 2006).

Os valores de DS observados nas áreas de $\mathrm{PN}, \mathrm{PP}, \mathrm{RF}$ e CE, os quais não diferem entre si, encontram-se abaixo dos valores referenciais de QS estabelecidos por Goedert (2005) e Papa et al. (2011), não sendo considerados como limitantes ou com potencial para causar danos ao crescimento radicular, e, consequentemente, ao pleno desenvolvimento das culturas.

Em todas as áreas amostrais, observou-se maior resistência à penetração à profundidade de 10,0-20,0 cm, em relação à profundidade de 0,0-10,0 cm, com diferença estatística nas áreas de PN, PP, RF e CE. Este aumento da RP em subsuperfície, particularmente em áreas de pastagens nativas e plantadas, pode decorrer do maior efeito descompactante do sistema radicular das gramíneas, nas camadas superficiais.

Os maiores valores de RP (Tabela 1) foram encontrados na $\mathrm{PP}$, nas duas profundidades avaliadas, refletindo o efeito do pisoteio de animais no solo, uma vez que a taxa de lotação, nesta área, está na faixa de 2,5 $\mathrm{UAha}^{-1}(\mathrm{UA}=$ Unidade Animal $)$, superior à média do Cerrado (aproximadamente $2 \mathrm{UA} \mathrm{ha}^{-1}$ ), no período de chuva, e chegando a $0,5 \mathrm{UA} \mathrm{ha}^{-1}$, no período de seca (Martha Júnior et al. 2003), considerando-se $1 \mathrm{UA}=450,0 \mathrm{~kg}$ de peso vivo.

Os maiores valores de RP observados na PP confirmam o relatado por Araújo et al. (2007), os quais observaram que, em solos sob pastagem formadas com capim braquiária, quando comparados com áreas de vegetação nativa, há aumento da compactação, à profundidade de $0,0-10,0 \mathrm{~cm}$. Deve-se ressaltar que o valor encontrado para PP, à profundidade de 10,0-20,0 cm, é considerado, por Goedert (2005) e Papa et al. (2011), superior ao nível limítrofe de sustentabilidade, que seria abaixo de $1 \mathrm{MPa}$. A PN também apresentou valor elevado de $\mathrm{RP}$, nas profundidades avaliadas, particularmente a de 10,0-20,0 cm, possivelmente resultante do efeito do pisoteio de animais no solo.

Nas áreas sob PN e PP, houve aumento da $\mathrm{RP}$, com o aumento da profundidade, o que pode ser atribuído à pressão exercida pelos animais, durante o pastoreio, sendo que, em profundidade inferior, a maior concentração de matéria orgânica minimiza o efeito da compactação (Reinert et al. 2008).

\section{Atributos químicos}

Os valores de $\mathrm{MO}$, nas áreas amostrais sob PP e CE, não diferiram entre e si e foram superiores aos observados nas demais áreas (Tabela 2). Estes resultados estão de acordo com os observados por Alvarenga \& Davide (1999) e Araújo et al. (2007), que não verificaram diferenças nos teores de matéria orgânica encontrados em ambientes de pastagem e de Cerrado, sugerindo serem estes ambientes conservadores, no que diz respeito aos teores de MO. Mendes \& Vivaldi (2001) sugerem valores em torno de $50,0 \mathrm{~g} \mathrm{~kg}^{-1}$, como valores ótimos, em relação à qualidade dos latossolos da região do Cerrado, tal como verificado para PP e CE.

$\mathrm{O}$ alto valor de MO encontrado para PP assemelha-se aos relatados por Kluthcousky \& 
Tabela 2. Teor de matéria orgânica (MO), capacidade de troca catiônica (CTC), carbono da biomassa microbiana (Cmic) e respiração basal (Rmic), à profundidade de 0,0-10,0 cm, em áreas sob diferentes tipos de uso da terra (Brazlândia, DF, 2005).

\begin{tabular}{|c|c|c|c|c|}
\hline \multirow{2}{*}{ Usos da terra } & $\mathrm{MO}$ & $\mathrm{CTC}$ & Cmic & Rmic \\
\hline & $\mathrm{g} \mathrm{kg}^{-1}$ & $\mathrm{cmol}_{\mathrm{c}} \mathrm{dm}^{-3}$ & $\mathrm{mg} \mathrm{C} \mathrm{kg}{ }^{-1}$ & $\mathrm{mg} \mathrm{C} \mathrm{kg}{ }^{-1} \mathrm{dia}^{-1}$ \\
\hline Agricultura com cobertura parcial do solo (AP) & $41,00 \mathrm{BC}$ & $9,65 \mathrm{~A}$ & $87,38 \mathrm{~B}$ & $10,15 \mathrm{C}$ \\
\hline Agricultura com solo coberto (AC) & $37,50 \mathrm{C}$ & $9,70 \mathrm{~A}$ & $155,80 \mathrm{AB}$ & $13,56 \mathrm{~B}$ \\
\hline Pastagem nativa $(\mathrm{PN})$ & $43,00 \mathrm{BC}$ & $7,80 \mathrm{~B}$ & $232,35 \mathrm{~A}$ & $11,48 \mathrm{BC}$ \\
\hline Pastagem plantada (PP) & $55,50 \mathrm{~A}$ & $9,45 \mathrm{~A}$ & $115,26 \mathrm{~B}$ & $25,82 \mathrm{~A}$ \\
\hline Reflorestamento (RF) & $45,00 \mathrm{~B}$ & $9,75 \mathrm{~A}$ & $187,11 \mathrm{AB}$ & $12,29 \mathrm{BC}$ \\
\hline Cerrado (CE) & $52,00 \mathrm{~A}$ & $9,30 \mathrm{~A}$ & $145,61 \mathrm{AB}$ & $13,57 \mathrm{~B}$ \\
\hline Valor de F & 42,98 & 37,78 & 7,85 & 114,31 \\
\hline C.V. $(\%)$ & 3,22 & 1,84 & 16,88 & 5,24 \\
\hline
\end{tabular}

Médias seguidas de mesma letra, na coluna, não diferem entre si, pelo teste Tukey, a 5\%.

Stone (2003), que afirmaram que os solos sob pastagem de braquiária são ricos em matéria orgânica, cujos teores são superiores aos do Cerrado nativo (Tabela 2). No Cerrado, o alto valor de MO, provavelmente, se deve ao predomínio de gramíneas e à diversidade e quantidade de vegetação da área sob Cerrado, aliados ao não revolvimento do solo, que mantém a MO protegida física e quimicamente (Resck et al. 1991).

A área de reflorestamento apresentou, também, alto teor de MO, apesar de inferior ao das áreas de PP e CE. Resultados semelhantes foram observados por Resck et al. (1991), em ambientes na região dos Cerrados, em que a pastagem, o Cerrado e áreas de reflorestamento tendem a apresentar maiores teores de matéria orgânica, quando comparados com ambientes cultivados. Araújo et al. (2007) constataram que, em áreas de reflorestamento, apesar da grande espessura da serapilheira, grande parte do seu material orgânico não está decomposto, em função da pequena superfície específica externa das acículas e da alta relação $\mathrm{C} / \mathrm{N}$, o que pode justificar o comportamento da MO na área de RF.

A área de agricultura com solo coberto (AC) apresentou o menor valor de $\mathrm{MO}$, considerado abaixo do limite de sustentabilidade de $40,0 \mathrm{~g} \mathrm{~kg}^{-1}$, segundo Goedert (2005) e Papa et al. (2011). Baixos teores de matéria orgânica, em áreas de agricultura, são comuns, devido ao revolvimento frequente do solo, que favorece a decomposição do material orgânico, e ao pequeno aporte de resíduos vegetais, semelhantemente ao relatado por Araújo et al. (2007).

Em áreas com produção de hortaliças, é usual a utilização de adubação orgânica. A área AP apresentou valor absoluto de MO superior ao de $\mathrm{AC}$, o que é compreensível, pois, normalmente, na região, a mandioca é cultivada após o uso da área na produção de hortaliças, aproveitando-se a adubação residual. Apesar de as áreas com agricultura terem apresentado baixos valores de matéria orgânica, não houve reflexo direto na resistência à penetração, o que pode ser atribuído ao revolvimento do solo por implementos agrícolas.

Áreas com pastagens naturais podem, também, apresentar baixos teores de matéria orgânica, em função do consumo da vegetação, e, como na área de PN não houve controle de lotação animal, provavelmente foi excessivamente pastoreada, resultando em baixo teor de MO (Tabela 2). Apesar do fato de a área de PN estar em pousio, há pelo menos um ano, antes da realização deste trabalho, o efeito do superpastejo ainda pode ser notado, uma vez que ocorre quebra do equilíbrio entre a reciclagem de nutrientes acumulados do resíduo vegetal e o crescimento da gramínea, tendo-se em vista que os nutrientes da forrageira não consumida, que permanecem no solo, são reaproveitados pelas próprias plantas forrageiras. Além disto, ocorre redução no vigor das plantas, capacidade de rebrotação e produção de sementes.

A capacidade de troca catiônica (CTC) foi menor na área sob PN, coincidindo com os baixos valores de MO nesta área, corroborando os efeitos do pastoreio excessivo, sendo que, nas demais áreas amostrais, estes não diferiram entre si (Tabela 2).

Os valores mais elevados de CTC, em relação à $\mathrm{PN}$, nas áreas de $\mathrm{AC}, \mathrm{AP}$ e RF, podem estar relacionados ao efeito da calagem que estas áreas receberam para sua implantação. Já nas áreas sob $\mathrm{PP}$ e CE, o valor da CTC pode estar relacionado ao efeito da matéria orgânica, uma vez que as áreas de $\mathrm{PP} \mathrm{e} C \mathrm{CE}$ foram as que apresentaram os maiores teores de MO (Tabela 2). 
Goedert (2005) e Papa et al. (2011) propuseram valores de CTC acima de $10,0 \mathrm{cmol}_{\mathrm{c}} \mathrm{dm}^{-3}$, como sendo ideais para este atributo na QS, em solos sob uso agrícola e sob vegetação nativa, respectivamente, para latossolos de regiões tropicais de textura argilosa, como é o caso da área em estudo, estando, assim, todas as áreas amostrais próximas a este limite, exceto a área de PN, que apresentou o menor valor.

\section{Atributos biológicos}

O carbono da biomassa microbiana (Cmic) foi maior na área sob PN, em relação a PP e AP, sendo que, para as demais, não houve diferença significativa (Tabela 2). O fato de não haver diferença significativa entre as áreas de Cerrado e pastagens plantadas já fora observado em outros estudos, como os de Araújo et al. (2007) e Carneiro et al. (2008, 2009), sugerindo que gramíneas plantadas desenvolvem um sistema radicular muito intenso, na camada superior do solo, favorecendo o desenvolvimento de micro-organismos, em relação às outras espécies cultivadas.

Neste estudo, não foi observada diferença nos valores de $\mathrm{Cmic}$, entre as áreas de $\mathrm{AP}, \mathrm{AC}, \mathrm{PP}$, RF e CE (Tabela 2), contrariando o observado por D'Andrea et al. (2002), em estudo realizado em Latossolo Vermelho distrófico argiloso, à profundidade de 0,0-5,0 cm, sob áreas de Cerrado, pastagem e plantio convencional, onde obtiveram valores de Cmic bem superiores aos encontrados neste trabalho, sendo verificada, no entanto, a mesma tendência decrescente nos valores de $\mathrm{Cmic}$, das áreas de Cerrado nativo para aquelas sob cultivo convencional.

Com relação à respiração basal (Rmic), que reflete a atividade da microbiota do solo, observou-se valor superior na área sob PP e inferior na área sob AP (Tabela 2). As áreas sob CE, RF, PN e AC não diferiram significativamente entre si. Resultados semelhantes foram observados por Matsuoka et al. (2003), Araújo et al. (2007) e Carneiro et al. (2008), que, também, evidenciaram tendência de superioridade da atividade microbiana, em solos sob PP, quando comparados a solos sob cultivos convencionais e áreas com vegetação nativa. Já Carneiro et al. (2009) observaram redução na relação $\mathrm{C}_{\mathrm{BMS}}: \mathrm{C}_{\text {org }}$, em solos cultivados com pastagem, em relação ao Cerrado.

Assim como constatado por Mendes \& Vivaldi (2001), não foi possível observar correlação entre a respiração basal (Rmic) e o carbono da biomassa microbiana (Cmic), e sim entre a Rmic e a MO, indicando a importância da MO para a atividade dos micro-organismos, no solo. Conforme dados apresentados na Tabela 2, os solos das áreas sob PP e CE apresentaram altos valores de MO.

\section{CONCLUSÕES}

1. Dentre os atributos de qualidade do solo avaliados, destacaram-se a matéria orgânica e a densidade do solo, que permitiram constatar que o uso agropecuário mais intensivo está diretamente relacionado à redução na qualidade do Latossolo Vermelho estudado.

2. Em relação aos atributos químicos e biológicos, o Latossolo Vermelho estudado mostrou problemas de qualidade, nas áreas amostrais que envolvem uso agrícola e na área sob pastagem nativa, especialmente com relação à matéria orgânica.

\section{AGRADECIMENTOS}

À Fundação de Apoio à Pesquisa do Distrito
Federal (FAPDF), pelo apoio financeiro.

\section{REFERÊNCIAS}

ALEF, K. Nitrogen mineralization in soils. In: ALEF, K.; NANNIPIERE, P. Methods in applied soil microbiology and biochemistry. London: Academic Press, 1995. p. 234245.

ALVARENGA, M. I. N.; DAVIDE, A. C. Características físicas e químicas de um Latossolo Vermelho-escuro e a sustentabilidade de agroecossistemas. Revista Brasileira de Ciência do Solo, Viçosa, v. 23, n. 4, p. 933-942, 1999.

ARAÚJO, R.; GOEDERT, W. J.; LACERDA, M. P. C. Qualidade de um solo sob diferentes usos e sob Cerrado nativo. Revista Brasileira de Ciência de Solo, Viçosa, v. 31, n. 1, p. 1099-1108, 2007.

ARSHAD, M. A.; MARTIN, S. Identifying critical limits for soil quality indicators in agro-ecosystems. Agricultural Ecosystems and Environment, Zürich, v. 88, n. 2, p. 153160, 2002.

BEUTLER, A. N. et al. Resistência à penetração e permeabilidade de Latossolo Vermelho distrófico típico sob sistemas de manejo na região dos Cerrados. Revista Brasileira de Ciência do Solo, Viçosa, v. 25, n. 1, p. 167177, 2001.

CAMARGO, O. A.; ALLEONI, L. R. F. Compactação do solo e o desenvolvimento das plantas. Piracicaba: ESALQ, 1997. 
CARNEIRO, M. A. C. et al. Atributos bioquímicos em dois solos de Cerrado sob diferentes sistemas de manejo e uso. Pesquisa Agropecuária Tropical, Goiânia, v. 38. n. 4, p. 276-283, 2008.

CARNEIRO, M. A. C. et al. Atributos físicos, químicos e biológicos de solo de Cerrado sob diferentes sistemas de uso e manejo. Revista Brasileira de Ciência do Solo, Viçosa, v. 33, n. 1, p. 147-157, 2009.

CARVALHO, R.; GOEDERT, W. J.; ARMANDO, M. $\mathrm{S}$. Atributos físicos da qualidade de um solo sob sistema agroflorestal. Pesquisa Agropecuária Brasileira, Brasília, DF, v. 39, n. 11, p. 1153-1155, 2004.

CHAVES, A. A. A. et al. Uso das terras da parte norte da Bacia do Rio Descoberto, Distrito Federal, Brasil. Bragantia, Campinas, v. 69, n. 3, p. 711-718, 2010.

CRUZ, A. C. R. et al. Atributos físicos e carbono orgânico de um Argissolo Vermelho sob sistemas de manejo. Revista Brasileira de Ciência do Solo, Viçosa, v. 27, n. 6, p. 11051112, 2003.

D'ANDREA, A. F. et al. Atributos biológicos da qualidade do solo em sistemas de manejo na região do Cerrado no sul do Estado de Goiás. Revista Brasileira de Ciência do Solo, Viçosa, v. 26, n. 4, p. 913-923, 2002.

DEXTER, A. R. Soil physical quality part I: theory, effects of soil texture, density, and organic matter, and effects on root growth. Geoderma, Amsterdam, v. 120, n. 3-4, p. 201-214, 2004.

DORAN, J. W.; PARKIN, T. B. Defining and assessing soil quality. In: DORAN, J. W. et al. (Eds.). Defining soil quality for a sustainable environment. Madison: Soil Science Society of America, 1994. p. 3-22.

EMPRESA BRASILEIRA DE PESQUISA AGROPECUÁRIA (Embrapa). Centro Nacional de Pesquisa de Solos. Manual de métodos de análise de solo. 2. ed. Rio de Janeiro: Embrapa Solos, 1997.

EMPRESA BRASILEIRA DE PESQUISA AGROPECUÁRIA (Embrapa). Centro Nacional de Pesquisa de Solos. Sistema brasileiro de classificação de solos. Brasília, DF: Embrapa Produção e Informação, 2006.

FOLONI, J. S. S.; CALONEGO, J. C.; LIMA, S. L. Efeito da compactação do solo no desenvolvimento aéreo e radicular de cultivares de milho. Pesquisa Agropecuária Brasileira, Brasília, DF, v. 38, n. 8, p. 947-953, 2003.

FONSECA, F. O. (Org.). Olhares sobre o Lago Paranoá. Brasília, DF: Secretaria de Meio Ambiente e dos Recursos Hídricos, 2001.

GOEDERT, W. J. Qualidade do solo em sistemas de produção agrícola. In: CONGRESSO BRASILEIRO DE
CIÊNCIA DO SOLO, 30., Recife, 2005. Anais... Recife: SBCS, 2005. 1 CD-ROM.

GOEDERT, W. J.; SCHERMACK, M. J.; FREITAS, F. C. Estado de compactação do solo em áreas cultivadas no sistema de plantio direto. Pesquisa Agropecuária Brasileira, Brasília, DF, v. 37, n. 2, p. 223-227, 2002.

JENKINSON, D. S.; POWLSON, D. S. The effects of biocidal treatments on metabolism in soil: a method for measuring soil biomass. Soil Biological Biochemistry, Brisbane, v. 8, n. 3, p. 209-213, 1976.

KLUTHCOUSKY, J.; STONE, L. F. Manejo sustentável dos solos dos Cerrados. In: KLUTHCOUSKY, J. (Ed.). Integração lavoura-pecuária. Santo Antônio de Goiás: Embrapa Arroz e Feijão, 2003. p. 61-104.

KONDO, M. K.; DIAS JÚNIOR, M. S. Compressibilidade de três latossolos em função da umidade e uso. Revista Brasileira de Ciência do Solo, Viçosa, v. 23, n. 2, p. 211218, 1999.

LAL, R. Métodos para avaliação do uso sustentável dos recursos solo e água nos trópicos. Jaguariúna: Embrapa Meio Ambiente, 1999. (Documentos, 3).

MARTHA JÚNIOR, G. B. et al. Uso de pastagem diferida no Cerrado. Planaltina, DF: Embrapa Cerrados, 2003. (Comunicado técnico, 102).

MATSUOKA, M.; MENDES, I. C.; LOUREIRO, M. F. Biomassa microbiana e atividade enzimática em solos sob vegetação nativa e sistemas agrícolas anuais e perenes na região de Primavera do Leste (MT). Revista Brasileira de Ciência do Solo, Viçosa, v. 27, n. 3, p. 425-433, 2003.

MELLONI, R. et al. Avaliação da qualidade de solos sob diferentes coberturas florestais e de pastagem no sul de Minas Gerais. Revista Brasileira de Ciência do Solo, Viçosa, v. 32, n. 6, p. 2461-2470, 2008.

MELO FILHO, J. F. et al. Análise estatística exploratória e variabilidade da densidade do solo em um perfil de Latossolo Amarelo coeso dos tabuleiros costeiros da Bahia. Ciência \& Agrotecnologia, Lavras, v. 30, n. 2, p. 199-205, 2006.

MENDES, F. G.; MELLONI, E. G. P.; MELLONI, R. Aplicação de atributos físicos do solo no estudo da qualidade de áreas impactadas, em Itajubá - MG. Cerne, Lavras, v. 12, n. 3. p. 211-220, 2006.

MENDES, I. C.; VIVALDI, L. Dinâmica da biomassa e atividade microbiana em uma área sob mata de galeria na região do DF. In: RIBEIRO, J. F.; SILVA, J. C. S.; LAZARINI, C. E. (Eds.). Conservação e recuperação da biodiversidade das matas de galeria do bioma Cerrado. Planaltina, DF: Embrapa Cerrados, 2001. p. 665-687. 
MENTGES, M. I. et al. Propriedades físico-hídricas do solo e demanda energética de haste escarificadora em argissolo compactado. Pesquisa Agropecuária Brasileira, Brasília, DF, v. 45, n. 3, p. 315-321, 2010.

MERCANTE, E.; URIBE-OPAZO, M. A.; SOUZA, E. G. Variabilidade espacial e temporal da resistência mecânica do solo à penetração em áreas com e sem manejo químico localizado. Revista Brasileira de Ciência do Solo, Viçosa, v. 27, n. 6, p. 1149-1159, 2003.

NORTCLIFF, S. Standardization of soil quality attributes. Agriculture Ecosystems and Environment, Zürich, v. 88, n. 2, p. 161-168, 2002.

PAPA, R. A. et al. Qualidade de Latossolos Vermelhos e Vermelho-Amarelos sob vegetação nativa de Cerrado. Pesquisa Agropecuária Tropical, Goiânia, v. 41, n. 4, p. 564-571, 2011.

REINERT, D. J. et al. Limites críticos de densidade do solo para o crescimento de raízes de plantas de cobertura em Argissolo Vermelho. Revista Brasileira de Ciência do Solo, Viçosa, v. 32, n. 5, p. 1805-1816, 2008.

RESCK, D. V. S.; PEREIRA, J.; SILVA, J. E. Dinâmica da matéria orgânica na região dos Cerrados. Planaltina, DF: Embrapa-CPAC, 1991.
SANTOS, M. L. et al. Correlação linear e espacial entre produtividade de milho (Zea mays L.) e atributos físicos de um Latossolo Vermelho distroférrico sob plantio direto do Cerrado brasileiro. Acta Scientiarum Agronomy, Maringá, v. 28, n. 3, p. 313-321, 2006.

SANTOS, R. D. et al. Manual de descrição e coleta de solos no campo. 5. ed. Viçosa: SBCS, 2005.

SECCO, D. et al. Atributos físicos e produtividade de culturas em um Latossolo Vermelho argiloso sob diferentes sistemas de manejo. Revista Brasileira de Ciência do Solo, Viçosa, v. 29, n. 3, p. 407-414, 2005.

SPERA, S. T. et al. Efeito de pastagens de inverno e de verão em características físicas de solo sob plantio direto. Ciência Rural, Santa Maria, v. 36, n. 4, p. 1193-1200, 2006.

TORMENA, C. A. et al. Densidade, porosidade e resistência à penetração em latossolo cultivado sob diferentes sistemas de preparo do solo. Scientia Agricola, Piracicaba, v. 59, n. 4, p. 795-801, 2002. 